\title{
Groundwater flooding risk in the cities of Ukraine: assessment and management
}

\author{
OLEKSANDR CHEBANOV ${ }^{\mathbf{1}}$ \& IRYNA KONOPLIA ${ }^{2}$ \\ 1SCIM UkrWogGeo, 6 Shevchenko Vul., Kharkiv, 61200 Ukraine \\ chebanov@uwodgeo.org.ua \\ 2UkrNIINTIZ, 38 Lenina Pr., Kharkiv, 61166 Ukraine
}

\section{INTRODUCTION: GROUNDWATER FLOODING (GWF)}

Development of the GWF phenomenon in an area takes place with the rising of the groundwater table up to the soil surface. The phenomenon appears in groundwater discharge areas in the forms of soils moistening, swamping, and flooding. In the urban areas of Ukraine it is often developed to a hazardous scale under the impact of a set of various causes and factors, and it results in complex changes in environmental conditions (Jakovlev et al. 2002). Local characteristics of urban development and geology determine the degree of GWF hazard related to an object (area or construction), and the vulnerability of the object to the hazardous impact. Assessment of GWF risk in urban areas might be useful for decision making to ensure geological safety, and during the process of development national and local actions plans (Chebanov and Konoplia 2010).

\section{GWF RISK ASSESSMENT}

A methodology for assessment GWF risk in urban areas based on expert and analytical evaluations (Kuzminand Chebanov 2004) has been applied in Ukraine.

When GWF risk is being assessed in relation to an object, then it is necessary to consider: the probability and degree of the hazardous impact, and, in addition, the vulnerability of the object to that impact. The phenomenon of the hazardous impact to the object is mostly external in character and is caused by climate and geology. The vulnerability of the object to the impact is dependent mostly on its own properties and characterizes its ability to withstand the impact injuries. Thus, during the risk assessment it is important to take into consideration the current condition of the object (constructions deterioration).

\section{Zoning the risk}

Techniques for zoning GWF risk (Chebanov and Zadniprovska 2011) includes GIS procedures for combining and overlapping different map layers. Input map layers reflect the spatial distribution of the hazardous processes characteristics and urban development characteristics, which are converted by means of these procedures into output layers of the hazard, vulnerability and risk factors distribution. In this step, models in computational intelligence should be applied together with other techniques. Input characteristics must be given at the points of a base grid of the area (city) map.

To perform risk zoning, the following thematic maps (layers) must be analysed:

1. groundwater depths;

2. concentrations of groundwater contaminants;

3. bearing capacity and presence of specific soils: subsiding, swelling, heaving;

4. urban development features (number of floors, underground structures, constructions deterioration, foundation type, functionality).

For example, the thematic maps were created for Kharkiv city by analysing urban development maps at scales from 1:500 to 1:10000 and recognizing 212 bordered areas having presence of some urban development features (Chebanov and Zadniprovska 2011). By that step there is 'encoding' of the geology and urban development data into hazard and vulnerability criteria. 
Finally, values of the hazard and vulnerability factors and the risk factor $R_{f}$ were assessed at the points of a base grid in the city map. Zoning of the risk on a city map is based on the graded scale: low - moderate - medium - high - critical (risks).

Creation of maps of GWF risk zoning for six large cities in Ukraine has been performed using GIS software. The base grids of these cities' maps include 357 points for Poltava, 406 points Kherson, 478 - Odessa, 579 - Zaporizhya, 1188 - Dnipropetrovsk, and 1348 - Kharkiv.

Figure 1 shows the GWF risk map obtained for Dnipropetrovsk city and industrial agglomeration. High GWF risk occurs mostly on lowlands.

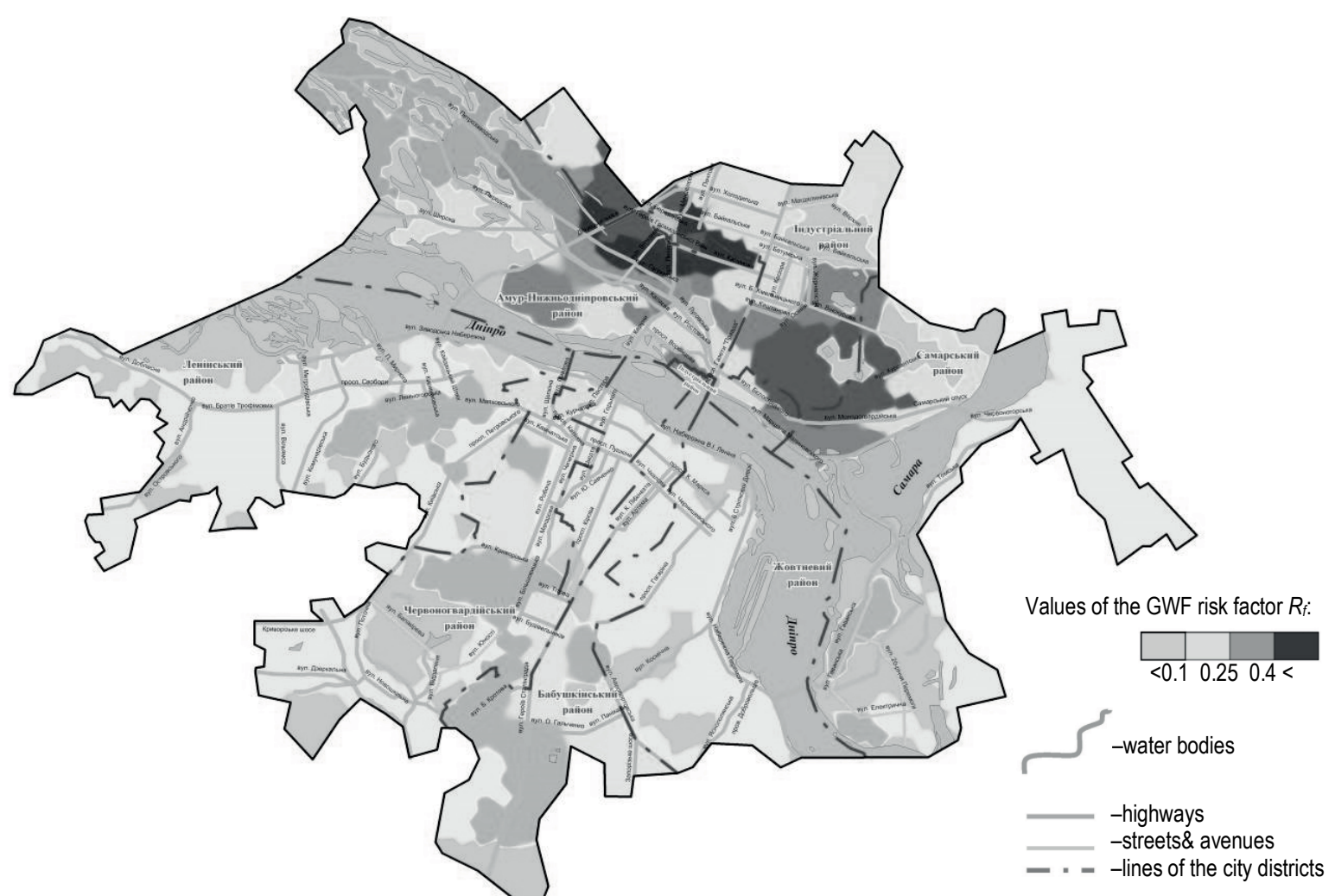

Fig. 1 Zoning GWF risk for Dnipropetrovsk city.

\section{GWF RISK MANAGEMENT}

It follows from consideration of the criteria for assessment of GWF risk, that management of that risk should include mostly engineering tools such as drainage, landscaping, and planning of land use and urban development. Also, for Ukraine it is important to improve the maintenance of water supply and sewer networks to avoid significant leaks from the pipes which can be a source of groundwater recharge. By some statistics, such leaks can achieve up to $70 \%$ of total water supply in localized areas.

\section{REFERENCES}

Chebanov, O. and Konoplia, I. (2010) Groundwater flooding in Ukraine: what kind of management does it require? In:Khan, S. et al. (eds.) Hydrocomplexity: New Tools for Solving Wicked Water Problems. Kovacs Colloquium UNESCO, Paris, France, July 2010:IAHS Publ. 338, 264-265.

Chebanov, O. and Zadniprovska, A. (2011) Zoning groundwater flooding risks in the cities and urban agglomeration areas of Ukraine. In: Bloeschl, G. et al. (eds) Risk in Water Resources Management. IAHS Publ. 347, 71-76.

Jakovlev, V. V., et al. (2002) Rising groundwater levels in northern-eastern Ukraine: hazardous trends in urban areas. In:Howard, K.W.F. and Israfilov,R.G. (eds.) Current Problems of Hydrogeology on Urban Areas. Urban Agglomerates and Industrial Centers. NATO Science Series: IV. Earth and Environmental Sciences, 8, 221-241.

Kuzmin, V. V.andChebanov, O. Ju. (2004) Assessment of risk and a property damages given by a land groundwater flooding. In:S. Razmetayev and V. Kostenko (eds.) Environment and a Human Health. Water and Air Basins Protection. Wastes Recycling. UkrWodGeo: Proc.XIIth Annual Conference, Berdiansk, Ukraine, June, 2004, vol. 1, 76-82 (in Russian). 